
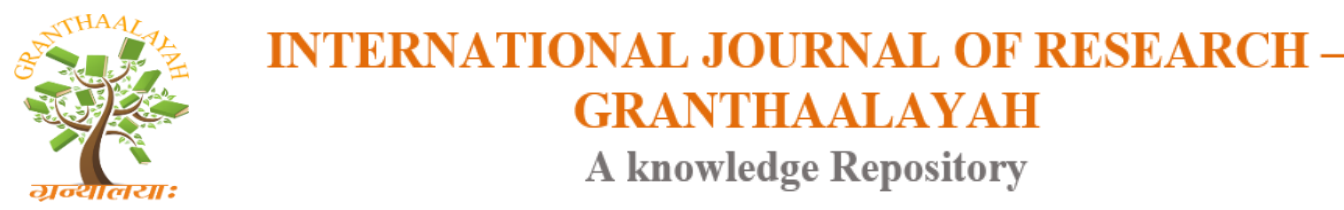

Science

\title{
MOLECULAR INTERACTION STUDIES OF ZWITTER- ION IN AQUEOUS SUCROSE AND ASCORBIC ACID AT CONSTANT TEMPERATURE
}

\author{
Yasmin Akhtar *1 \\ ${ }^{* 1}$ Department of Chemistry, University of Tabuk, Tabuk, Saudi Arabia. Al-Falah University*, \\ Faridabad, Haryana, India
}

\begin{abstract}
Density and viscosity of L-Arginine in aqueous sucrose and ascorbic acid solutions have been determined experimentally at $298 \mathrm{~K}$. The results obtained from density and viscosity measurement have been used to calculate the Hydration number $\mathrm{H}_{\mathrm{n}}$, apparent molar volume $\phi_{\mathrm{v}}$, partial molal volume $\phi^{0}{ }_{\mathrm{v}}$, at infinite dilution, transfer volume $\Delta \phi^{0}{ }_{\mathrm{tr}}$ and $\mathrm{B}$ - coefficient. It has been observed that there exist strong solute-solvent interaction and complex formation between in these ternary systems. The properties of this amino acid in water and aqueous sucrose and ascorbic acid systems are discussed in terms of the charge, size and hydrogen bonding effect.
\end{abstract}

Keywords: L-Arginine; Sucrose; Ascorbic Acid; Hydration Number; Apparent Molal Volume; And Transfer Volume.

Cite This Article: Yasmin Akhtar. (2018). "MOLECULAR INTERACTION STUDIES OF ZWITTER- ION IN AQUEOUS SUCROSE AND ASCORBIC ACID AT CONSTANT TEMPERATURE." International Journal of Research - Granthaalayah, 6(9), 356-363. https://doi.org/10.5281/zenodo.1451866.

\section{Introduction}

In continuation of our earlier work [1] on the study of interaction between amino acids and electrolytes in aqueous medium, we present in this paper, the study of interaction between aqueous L-Arginine in aqueous sucrose and ascorbic acid at $298 \mathrm{~K}$. There has been an increased interest in the physicochemical properties of amino acids and carbohydrates in aqueous as well as aqueous electrolyte media to understand the role played by the biological molecules in living organism [26]. Amino acids have zwitter-ion and are the constituents of the most important class of biopolymers, i.e. Proteins. Disarrangement water and electrolyte balance in living systems cause a wide variety of health problems. In physiological media such as blood, membranes, cellulose fluids etc., the dipolar character of amino acids (in presence of ions such as $\mathrm{Na}^{+}, \mathrm{K}^{+}, \mathrm{Mg}^{+2} \mathrm{and} \mathrm{Cl}^{-}$ etc., dissolved in body water) has an important bearing on their biological functions. Therefore, a knowledge of water-amino acid interaction the effects on several biological processes occurring in living organism. In recent years, a number of workers have utilized density and viscosity data 
to deduce the thermodynamic properties (relative viscosity, Jones -Dole coefficient and free energy of activation of viscous flow) for a number of mixtures solutions [7-9]. Structural interactions of non-ionic solutes with ionic ones in different solvents are important in many fields of chemistry and bio-chemistry. Very recently, we have made systematic effort to investigate the ultrasonic and volumetric properties of amino acids in concentrated electrolytic solution [10-12]. It was found that $\mathrm{NaCl}$ and $\mathrm{MgCl}_{2}$ increase the apparent molar volume and decrease the adiabatic compressibility of glycine. This increase could be attributed to the interactions of the ions of the $\mathrm{NaCl}$ and $\mathrm{MgCl}_{2}$ electrolytes and zwitter-ion head group of glycine, causing the transfer of hydrated water molecule to the bulk state.

In the present paper, we report densities, $\rho$ and viscosities, of L-Arginine $(0.05,0.10,0.15,0.20$, 0.25 and 0.3$) \mathrm{m}$ in aqueous sucrose and ascorbic acid solutions have been determined experimentally at $298 \mathrm{~K}$. From these experimental data a number of thermodynamic parameters namely, Hydration number $H_{n}$, apparent molar volume $\phi_{\mathrm{v}}$, partial molal volume $\phi_{\mathrm{v}}^{0}$, transfer volume $\Delta \phi_{\text {tr }}^{0}$ and B-coefficient at infinite dilution respectively have been calculated. These parameters were utilized to study various interactions taking place in the solutions of L-Arginine in aqueous sucrose and ascorbic acid at $298 \mathrm{~K}$.

\section{Material and Methods}

L-Arginine (99\% purity), sucrose and ascorbic acid (99.8\% purity) were procured from Merck and $\mathrm{S} d$ Fine Ltd. They were used as such without further purification, after drying over calcium chloride in desiccators for more than 48 hours. The ultrasonic velocities and densities of the amino acid in aqueous sucrose and ascorbic acid solutions at various concentrations as well as in double distilled de-ionized water were measured experimentally. Aqueous solutions of sucrose and ascorbic acid were prepared and these were used as solvents to prepare L-Arginine solutions on mass basis covering the whole composition range. All the solutions were prepared by mass in dry box and were stored in special air-tight bottles and kept in dark to avoid photo chemical degradation. The weighing was done on an Afcoset ER-120A electronic balance with an accuracy $\pm 0.1 \mathrm{mg}$.

The densities were measured with a single capillary pycnometer (made of Borosil glass) of bulb capacity of $8 \times 10^{-6} \mathrm{~m}^{3}$. The marks of the stems were calibrated using double distilled water at 298 $\mathrm{K}$. The pycnometer was kept for about 30 minutes in a thermostatic water bath so that the thermal fluctuation in density was minimized. The viscosities in solutions were measured using Ostwald viscometer. At least three time recorded were obtained, and the average value was used as the experimental flow time. Poiseuille's equation was employed to calculate the viscosity of the amino acid + electrolyte + water solutions.

$$
\eta=\frac{\Pi \rho h g r 4 t}{81 \mathrm{~V}}=\rho \beta \mathrm{t}
$$

Here $\rho$ is the density of the amino acids solutions, $h$ the height of the column in the viscometer, $g$ is the acceleration due to gravity, $r$ is the radius of the capillary, 1 the length capillary and $t$ is the time of fall off the solution of volume V. The term $h, g, r, 1$ and $V$ are constant for a given 
viscometer therefore theses have been replaced by single term $\beta$. The temperature of the test solutions was maintained at $298 \pm 0.02 \% \mathrm{~K}$ in an electronically controlled thermostatic water bath. The viscosity and density data were found to be accurate with in $\pm 0.01 \%$ and $\pm 0.01 \%$ respectively.

\section{Result and Discussion}

The densities, $\rho$ and viscosities, of L-Arginine $(0.05,0.10,0.15,0.20,0.25$ and 0.3$) \mathrm{m}$ in aqueous sucrose and ascorbic acid solutions have been determined experimentally at $298 \mathrm{~K}$. are presented in Table 1. It is observed from Table 1 that densities and viscosities for all the ternary systems increase with increase in molalities of L-Arginine. The values of $\rho$ and $\eta$ increase with increase in concentration of amino acid in all the ternary systems under investigation, which appear to be due to hydrophobic properties of solutes i.e. H-bond forming. This may be attributed to the formation of clusters by the amino acids and strong intermolecular forces in the solute. The changes in structure of solvent or solution as a result of $\mathrm{H}$ - bond formation lead to decrease in intermolecular free length [13]. Solute may occupy the interstitial spaces in solvent or get solvated forming new weaker bonds. It was suggested [14-16] that what is experimentally observed for any system, reflects the compromise between the tendency for the ion and the peptide to interact with each other and inclination of the solutes to associate with the solvent.

Table 1: Densities $(\rho)$ and Viscosities $(\eta)$ of Arginine + aqueous Sucrose and Ascorbic acid solutions at $298 \mathrm{~K}$

\begin{tabular}{|c|c|c|c|c|}
\hline $\mathrm{C}$ (mol.dm-1) & $\rho(\mathrm{g} \mathrm{cm}-3)$ & $\eta$ (mPa.s) & $\rho(\mathrm{g} \mathrm{cm}-3)$ & $\eta$ (mPa.s) \\
\hline \multicolumn{5}{|c|}{ L-Arginine +aqueous Sucrose } \\
\hline$(0.15) \mathrm{m}$ & & & $(0.30) \mathrm{m}$ & \\
\hline 0.00 & 1.0175 & 1.0116 & 1.0375 & 1.1817 \\
\hline 0.05 & 1.0190 & 1.0485 & 1.0419 & 1.2032 \\
\hline 0.10 & 1.0230 & 1.0744 & 1.0427 & 1.2453 \\
\hline 0.15 & 1.0243 & 1.1052 & 1.0443 & 1.3111 \\
\hline 0.20 & 1.0257 & 1.1354 & 1.0467 & 1.3541 \\
\hline 0.25 & 1.0301 & 1.1957 & 1.0513 & 1.4372 \\
\hline \multicolumn{5}{|c|}{ L-Arginine +aqueous L-ascorbic acid } \\
\hline$(0.3) \mathrm{m}$ & & & $(0.60) \mathrm{m}$ & \\
\hline 0.00 & 1.0176 & 0.9887 & 1.0375 & 1.1817 \\
\hline 0.05 & 1.0202 & 1.0021 & 1.0391 & 1.1342 \\
\hline 0.10 & 1.0240 & 1.0298 & 1.0422 & 1.1731 \\
\hline 0.15 & 1.0252 & 1.0597 & 1.0444 & 1.2221 \\
\hline 0.20 & 1.0301 & 1.0957 & 1.0465 & 1.2607 \\
\hline 0.25 & 1.0323 & 1.1234 & 1.0480 & 1.2988 \\
\hline 0.30 & 1.0352 & 1.1612 & 1.0512 & 1.3473 \\
\hline
\end{tabular}

The apparent molal volume, $\phi_{\mathrm{v}}$ were calculated from measured density data of L-Arginine in aqueous sucrose and ascorbic acid solutions have at $298 \mathrm{~K}$ using the following equation:

$\phi_{\mathrm{v}}=\left[1000\left(\rho^{0}-\rho\right) / \mathrm{m} \rho \rho^{0}\right]+\mathrm{M} / \rho$ 
Where $M$ is the molecular mass of the solutes, $\rho^{0}$ and $\rho$ are densities of solvent and solution. The calculated values of $\phi_{v}$ of these ternary systems are given in Table 2 . In these cases where molality dependence of $\phi_{\mathrm{v}}$, having no definite trend points, the $\phi_{\mathrm{v}}$ values increase due to reduction in the electrostriction effect at terminals, whereas it decreases due to disruption of side group hydration by that of the charged end.

Table 2: Apparent molal volume ( $\phi v)$ and Hydration number (Hn) of Arginine + aqueous Sucrose and Ascorbic acid solutions at $298 \mathrm{~K}$

\begin{tabular}{|c|c|c|c|c|}
\hline m (mol.kg-1) & фv (cm3 mol-1) & Hn & Фv (cm3 mol-1) & Hn \\
\hline \multicolumn{5}{|c|}{ L-Arginine +aqueous Sucrose } \\
\hline$(0.15) \mathrm{m}$ & & & $(0.30) \mathrm{m}$ & \\
\hline 0.00 & - & 2.70 & - & 2.80 \\
\hline 0.05 & 124.46 & 2.21 & 124.62 & 2.22 \\
\hline 0.10 & 124.43 & 2.20 & 124.52 & 2.23 \\
\hline 0.15 & 124.20 & 2.19 & 124.38 & 2.20 \\
\hline 0.20 & 124.15 & 2.14 & 124.31 & 2.15 \\
\hline 0.25 & 123.63 & 1.13 & 123.73 & 1.15 \\
\hline 0.30 & 123.48 & 1.01 & 123.54 & 1.05 \\
\hline \multicolumn{5}{|c|}{ L-Arginine +aqueous L-ascorbic acid } \\
\hline$(0.3) \mathrm{m}$ & & & $(0.60) \mathrm{m}$ & \\
\hline 0.00 & - & & - & 6.58 \\
\hline 0.05 & 112.49 & 5.82 & 114.59 & 5.84 \\
\hline 0.10 & 112.39 & 5.01 & 114.46 & 5.04 \\
\hline 0.15 & 112.31 & 4.82 & 114.30 & 4.85 \\
\hline 0.20 & 112.16 & 4.78 & 114.12 & 4.82 \\
\hline 0.25 & 112.03 & 4.80 & 113.60 & 4.81 \\
\hline 0.30 & 111.96 & 4.78 & 113.38 & 4.80 \\
\hline
\end{tabular}

The partial molal volume at infinite dilution $\phi^{\circ}{ }_{\mathrm{v}}$ was calculated by taking an average data points. The linear variation is obtained by least square fitting to the following equation.

$\Phi_{\mathrm{v}}=\phi^{0}{ }_{\mathrm{v}}+\mathrm{S}_{\mathrm{v}} \mathrm{m}^{1 / 2}$

The intercept $\phi^{0}{ }_{\mathrm{v}}$ which is the partial molal volume at infinite dilution and $S_{\mathrm{v}}$ is the experimental slope, which is considered to be volumetric pair wise coefficient. The derived values $\phi^{0}{ }_{\mathrm{v}}$ are summarized in Table 2 . Table 2 shows that the values of $\phi^{0}{ }_{\mathrm{v}}$ are positive of these ternary systems which indicate ion-solvent interactions are strong. The positive value of $\phi^{0}{ }_{v}$ with sucrose and ascorbic acid concentration of water molecules as a result of shielding of polar terminal groups of L-Arginine molecules is due to increased interaction between these sucrose and ascorbic acid aqueous solution. These results can be explained by the coshere overlap model as developed by Friedmann et al. [17] the properties of water molecules in the hydration cosphere depends on the nature of solute species.

The types of interactions occurring between the zwitter ions of L-Arginine and $\mathrm{OH}^{-}$group of sucrose and ascorbic acid can be classified as follows: 
- hydrophilic interaction between $-\mathrm{NH}_{3}{ }^{+}$and $\mathrm{COO}^{-} \mathrm{L}$-Arginine with $\mathrm{OH}^{-}$group of sucrose and ascorbic acid.

- The terminal groups of zwitter ions of amino acid $-\mathrm{NH}_{3}{ }^{+}$and $\mathrm{COO}^{-}$are hydrated in electrostatic manner.

- The overlap of hydration co spheres of terminal groups $\left(\mathrm{NH}_{3}{ }^{+}\right.$and $\left.\mathrm{COO}^{-}\right)$and of adjacent groups results in volume change.

- Hydrophilic and hydrophobic interactions between the $\mathrm{OH}^{-}$group of sucrose and ascorbic acid and non-polar group- $\left(\mathrm{CH}_{2}\right)$ of L-Arginine.

- Hydrophobic and hydrophobic interactions between the non-polar group of sucrose and ascorbic acid and non-polar group- $\left(\mathrm{CH}_{2}\right)$ of L-Arginine.

The transfer volume of L-Arginine from pure water and aqueous sucrose and ascorbic acid solution were calculated using the following equation

$\Phi_{\mathrm{v}(\mathrm{tr})}^{0}=\phi_{\mathrm{v}}^{0}($ aq. sugar $)-\phi_{\mathrm{v}}^{0}(\mathrm{aq})$

These values are presented in Table 3, which shows to be positive in sucrose and negative in ascorbic acid systems at $298 \mathrm{~K}$. The change in values of $\Phi^{0}{ }_{\mathrm{v}(\mathrm{tr})}$ are interpreted on the basis of cosphere overlap model given be Friedman and Krishnan [17]. According to this model overlap of co-sphere make the positive contribution to the transfer volume in sucrose, since the overlap of hydration co-sphere of two terminal groups $\left(\mathrm{NH}_{3}{ }^{+}\right.$and $\left.\mathrm{OH}^{-}\right)$leads to increase the in magnitude of hydrogen bonding interaction which reflect increase in volume. The interactions of ascorbic acid makes the negative contribution to the transfer of volume and it may be that ascorbic acids gives $\mathrm{H}^{+}$to arginine, which leads to an increase in electrostriction effect of the water caused by these ions. Mishra et al [18] have suggested eq. (5) which shows that limiting apparent molar volume of amino acids is made up of vander volume $\left(\mathrm{V}_{\mathrm{vw}}\right)$, volume associated with empty space $\left(\mathrm{V}_{\mathrm{v}}\right)$ and volume due to shrinkage $\left(\mathrm{V}_{\mathrm{s}}\right)$, mainly due to electrostriction of solvent by the terminal charge centre of the amino acids.

$\mathrm{V}_{\Phi}=\mathrm{V}_{\mathrm{vw}}+\mathrm{V}_{\mathrm{v}}+\mathrm{V}_{\mathrm{S}}$

Table 3: Limiting apparent molal volume ( $\Phi 0 \mathrm{v})$, Transfer volume ( $\Delta \Phi 0$ tr $)$ and viscosity Bcoefficient of Arginine + aqueous Sucrose and Ascorbic acid solutions at $298 \mathrm{~K}$

\begin{tabular}{|l|l|l|l|}
\hline $\mathbf{m}$ & Ф0v & $\Delta \Phi 0 t r$ & \\
\hline $\mathbf{B}$ & & & \\
\hline mol. Kg-1 & (cm3 mol-1) & $\mathbf{( c m 3 ~ m o l - 1 )}$ & (dm3.mol-1) \\
\hline Sucrose +water & & & \\
\hline 0.15 & 124.7 & 1.7 & 0.613 \\
\hline 0.30 & 125.0 & 1.9 & 0.732 \\
\hline Ascorbic+ water & & & \\
\hline 0.30 & 112.5 & -10.3 & 0.650 \\
\hline 0.60 & 115.2 & -7.7 & 0.794 \\
\hline
\end{tabular}

These tendencies can also be explained using the co-sphere overlap model [17]. According to this model, hydrophilic-ionic group interactions contribute positively, whereas ionic hydrophobic group interaction contribute negatively values of $\Phi_{\mathrm{v}(\mathrm{tr})}^{0}$. The values of transfer volume of arginine 
are positive in aqueous sucrose solution due to hydrophilic-ionic group interactions which leads of a decrease in the structure breaking tendency of the ion and a reduction in the electrostriction of the water caused by these ions.

The standard partial molal volumes of arginine can be expressed from a simple model [19]

$\phi^{0}{ }_{\mathrm{v}}=\phi_{\mathrm{v}}^{0}($ intr $)+\phi^{0}{ }_{\mathrm{v}}(\mathrm{elect})$

where $\phi_{\mathrm{v}}^{0}$ (intr) is the intrinsic partial molal volume and $\phi^{0}{ }_{\mathrm{v}}(\mathrm{elect})$ is the electrostriction partial molal volume due to hydration of arginine. The $\phi^{0}{ }_{\mathrm{v}}$ (intr) is made up of two terms., the Van der waals volume due to packing effects. The $\phi^{0}{ }_{\mathrm{v}}$ (intr) can be calculated by crystal molal volumes. According to the suggestion of Millero et al [20], the values of $\phi^{0}{ }_{\mathrm{v}}$ (intr) for arginine can be estimated from crystal molal volumes.

$\phi^{0}{ }_{\mathrm{v}}(\mathrm{intr})=(0.7 / 0.634) \phi^{0}{ }_{\mathrm{v}}(\mathrm{cryst})$

where 0.7 is the packing density for molecules in organic crystals and 0.634 is the packing density for random packing spheres. The crystal molal volume can be calculated by the following equation:

$\phi^{0}{ }_{\mathrm{v}}($ cryst $)=\mathrm{M}_{\mathrm{s}} / \rho($ cryst $)$

where $\rho$ (cryst) is the crystal density of arginine [21]. The $\phi^{0}{ }_{v}($ elect $)$ can be estimated by

$\phi^{0}{ }_{\mathrm{v}}(\mathrm{elect})=\phi_{\mathrm{v}}^{0}-\phi_{\mathrm{v}}^{0}($ intr $)$

The decrease in volume due to electrostriction can be related to the hydration number of water molecules (Hn) is hydrated arginine [21].

$\mathrm{H}_{\mathrm{n}}=\phi_{\mathrm{v}}^{0}(\mathrm{elect}) /\left(\phi_{\mathrm{v}(\mathrm{E})}-\phi_{\mathrm{v}(\mathrm{B})}\right)$

Where $\phi_{\mathrm{v}}(\mathrm{E})$ is the molal volume of electrostricted water and $\phi_{\mathrm{v}}(\mathrm{B})$ is the molal volume of bulk water at $298 \mathrm{~K}$ are described by Millero et.al

$\phi_{\mathrm{v}(\mathrm{E})}-\phi_{\mathrm{v}(\mathrm{B})}=-3.3 \mathrm{~cm}^{3} / \mathrm{mol}$

Therefore, as an approximation, the hydration number of water molecules can be obtained as

$\mathrm{H}_{\mathrm{n}}=\phi_{\mathrm{v}}^{0}(\mathrm{elect}) /-3.3$

The $\mathrm{H}_{\mathrm{n}}$ value of arginine in aqueous sucrose and L-ascorbic acid solutions are shown in Table 2.

It can be seen that $\mathrm{H}_{n}$ of arginine decreases with increasing concentration of sucrose and ascorbic acid. These shows that sucrose and ascorbic acid have dehydration effect on the arginine.

The viscosity data were used to calculate the relative viscosity using Jones- Dole equation [] 
$\eta_{\text {rel }}=\eta / \eta_{\mathrm{o}}=[1+\mathrm{Bm}]$

Where, $\eta$ and $\eta_{\mathrm{o}}$ viscosities of the solutions and solvent respectively. B, is the Jones- Dole coefficient [22], an empirical constant, and is measure of ion-solvent interaction. Its values depend on the size and shape of the solute particles. They were obtained by a least square treatment as the intercepts and slopes of the linear plots of $\eta / \eta_{\mathrm{o}^{-}} 1 / \mathrm{m}^{1 / 2}$ versus $\mathrm{m}^{1 / 2}$ and their values are given in Table 2.

For a dilute solution of unsolvated spherical colloidal suspension, has derived by Einstein relation

$\eta_{\text {rel }}=1+2.5 \varphi$

Where $\varphi$ is the volume fraction of the solute. If this equation is valid or amino acids, Eq. (3) becomes

$\eta_{\text {rel }}=1+0.0025 \mathrm{~V}_{\mathrm{hC}}$

Where $\mathrm{V}_{\mathrm{h}}$ is the hydrodynamic volume. For a dilute solution, the following relation holds

$\mathrm{B}=0.0025 \mathrm{~V}_{\mathrm{h}}$

Hakin et.al (23) may be assumed that the partial molar volume at infinite dilution of the unsolvated solute particle in a continuum solvent. The more B values in the mixed solvent might mean a more hydrodynamic volume in the mixed solvent. The viscosity B-coefficient is valuable to provide information concerning of solvation of solute and their effects on the structure of the solvent. The B- coefficient values are positive and large which indicates the solute-solvent interaction are strong are shown in Table 3. The B- coefficient increase when water is replaced by sucrose and ascorbic acid are acting as a water structure maker through the $\mathrm{H}$-bonding.

\section{Conclusion}

The volume data have been used to study of solute-solvent interaction in these ternary systems. The polar terminal groups of L-Arginine molecules is due to increased interaction between these sucrose and ascorbic acid aqueous solution It can be concluded that the existence of molecular interaction is in the order of sucrose $>$ ascorbic acid. This suggests L-Arginine in aqueous sucrose solution is strong structure maker than L-Arginine in aqueous ascorbic acid. The positive value of $\Delta \Phi_{\text {tr }}^{0}$ of L-Arginine from water to aqueous sucrose solutions show that the interactions involving the charged Centre of peptide as well as ions are dominating.

\section{References}

[1] Yasmin Akhtar, October (2017) International J. Res. Granth. 5(10) 160-

[2] Yasmin Akhtar, (2015) International J. Sci. Tech. \& Soc. 3(4) 6-9. Yasmin Akhtar, (2014) Journal of International Academic Research for Multidisciplinary2 (5) 694-700.

[3] Y. Akhtar (2017) Int. J. Sci. \& Res. Meth. 7(3) 139-149. 167and Y. Akhtar, S. F. Ibrahim, (2011) Arabian J. Chem. 4 487-490.

[4] Yasmin Akhtar, (2015) International J. Engg. Sci. \& Res. Tech. 4(9) 649. 
[5] X. Jiang, C. Zhu and Y. Ma, (2014) J. Chem. Thermodyn. 7150-63.

[6] M. S. Hussain, T.K Kabriaz, M. N. Islam and M. E. Haque, (2014) J. Chem. Thermodyn. 71 6-13.

[7] A. P. Mishra and S. K. Gautum, (2001) Indian J. Chem. 40A 100.

[8] J. N. B. Mallick, R. K. Mohanty and U. Chakraborty, (1986) Indian J. Chem. 25A 1089.

[9] M. S. El-Eazby, J.M. Al- Hassan, N.F. Eweissdan F. AL-Massad, (1979) Can. J. Chem. 57 104114.

[10] Yasmin Akhtar, 2009 J. International Acad. Res. Multi. Dis. (8) (2015) 39. Y. Akhtar, Indian J. Phy. Chem. 4 (1).

[11] Y. Akhtar, (2007) Inver. J. Sci .and Tech. 5 (3) (2012) 171-173. Y. Akhtar, Fluid Phase Equil. 258 125.

[12] T. S. Banipal and G. Singh (2000) Indian J. Chem. 3A 1011.

[13] A. P. Mishra and S. K. Gautum , (2001), Indian J. Chem. 40A 100 and D. L. Q. Yu, Y. Y. Wang and D. Sun Indian J. Chem. (2002) 41A 1126.

[14] R. J. Laurich, C. R. Torok and M. J. Tubergen (2002) J. Phys. Chem.A 1068013.

[15] B. N. Waris, U. Hassan, N. Srivastava, (2001) Indian J. Chem. 40A 1218.

[16] K. Karl, B. Alex and N. Kishore, (2002) J. Chem. Thermodyn. 34319.

[17] H. I. Fried man, C.V. Krishnan, 1973 Water a Comprehensive Treatise. Vol. 3 New York,. And M. Iqbal, M. Mateullah (1990) Can. J. Chem. 687

[18] A. P. Mishra and S. K. Gautam, (2001) Indian J. Chem. 40A 100G.

[19] F. Franks, M. A. Quickenden, D. S. Reid, B. Watson, (1970) Trans Faraday Sc. Trans I. 69582586.

[20] F. J. Millero, A. Losurdo, C. Shin, (1978) J. Phys. Chem. 82 1887-784-792.

[21] E. Berlin, M. J. Pallasch. (1968) J. Phys. Chem. 72 1887-1889.

[22] Jones and M. Dole, (1929) J. Am. Chem. Soc. 512950.

[23] A. W. Hakin, M. M. Duck, J. L. Marty, K. E. Preuss, J. Chem. Soc. Faraday Trans. 90 (1994)20272037.

\footnotetext{
*Corresponding author.

E-mail address: dryasminakhtar2004@ yahoo.com
} 